\title{
Dental fluorosis in permanent incisor teeth in relation to water fluoridation, social deprivation and toothpaste use in infancy
}

\author{
E. D. Tabari, ' R. Ellwood, ${ }^{2}$ A. J. Rugg-Gunn, ${ }^{3}$ D. J. Evans, ${ }^{4}$ and R. M. Davies, ${ }^{5}$
}

\begin{abstract}
Objectives To determine the prevalence and severity of fluorosis in permanent incisor teeth in young children in a fluoridated and a fluoride-deficient community and to establish what relationship, if any, there was between the occurrence of dental fluorosis and the reported use of fluoride toothpaste in childhood.
\end{abstract}

Design A prevalence study of children aged 8-9 years who had been continuous residents in fluoridated Newcastle or fluoridedeficient Northumberland.

Method The permanent maxillary central incisor teeth were examined clinically and photographically by one examiner using the Thylstrup-Fejerskov index; the photographs were read blind to child identity and clinical score. A closed-response questionnaire enquired into the child's early experiences of toothbrushing and use of fluoride toothpastes. Social deprivation was measured by a Jarman score. The study took place in 1998.

Outcome measure Prevalence of dental fluorosis measured by the Thylstrup-Fejerskov index.

Results Complete data were available for $78 \%(n=409)$ and $79 \%(n=403)$ of eligible sampled children in the two areas, respectively. Clinical and photographic results agreed closely and had high reproducibility. The prevalence of fluorosis was $54 \%$ in the fluoridated area and $23 \%$ in the fluoride-deficient area when all grades $(>0)$ of fluorosis were included; percentage prevalence of mild to moderate fluorosis $(\geq 3)$ was $3 \%$ and $0.5 \%$ in the two areas, respectively. Multivariate analysis indicated that area of residence (odds ratio $=4.5)$, Jarman score $($ odds ratio $=0.99$ per Jarman unit) and type of toothpaste (odds ratio $=1.6$ ) were statistically significantly related to presence or absence of fluorosis: the risk factors were - fluoridated area, affluence, and use of adult toothpaste.

Conclusions and recommendations The prevalence of aesthetically important dental fluorosis was low, although higher

${ }^{1}$ Senior Dental Officer, Newcastle City Health NHS Trust, Walkergate Centre 45 Scrogg Road, Walker, Newcastle upon Tyne NE6 4EY; ${ }^{2}$ Technology Manager,

${ }^{5}$ Director, Dental Health Unit, Manchester University, Unit 3 A Skelton House, Manchester Science Park, Lloyd Street North, Manchester M15 4SH; ${ }^{3}$ Professor of Preventive Dentistry, Newcastle University Dental School, Framlington Place, Newcastle upon Tyne NE2 4BW; ${ }^{4}$ Consultant in Dental Public Health, Newcastle $\&$ North Tyneside and Northumberland Health Authorities, Benfield Road, Newcastle upon Tyne NE6 4PF

Correspondence to: $D$. Tabari

email:Tabari@BTinternet.com

REFEREED PAPER

Received 25.10.99; accepted 09.03.00

(c) British Dental Journal 2000; 189: 216-220 in the fluoridated area. Use of a child's toothpaste (with lower fluoride concentration) could decrease risk in a fluoridated area. Adherence to the guidelines published by the British Society of Paediatric Dentistry is recommended.

There is concern that the prevalence of dental fluorosis may be 1 rising in both fluoridated and non-fluoridated communities. ${ }^{1-3}$ Although a review of available data failed to substantiate this claim on a population basis in the United Kingdom, ${ }^{4}$ concern about the prevalence of fluorosis has prompted a number of studies to assess fluorosis risk when different fluoride delivery systems are used.

The benefits of fluoride toothpastes have been demonstrated unequivocally but their use by very young children has been identified as a potential risk factor for fluorosis. The age brushing commenced, ${ }^{5-9}$ the frequency of brushing, ${ }^{8,10}$ the fluoride concentration $^{8}$ and the amount of toothpaste applied to the toothbrush ${ }^{8}$ and subsequently swallowed ${ }^{11}$ have all been implicated as potential fluorosis risk factors. Although most of the fluorosis observed is of no aesthetic concern to those affected or their families, there is a need to establish what contribution fluoride toothpastes make to fluorosis risk, ${ }^{4}$ so that health education messages to the parents of young children are clear and unambiguous.

The aim of this study was to determine the prevalence and severity of fluorosis in permanent incisor teeth in young children in a fluoridated and a non-fluoridated community and to establish what relationship, if any, there was between the occurrence of dental fluorosis and the reported use of fluoride toothpaste in childhood. The study design was based on that described by Rock and Sabieha ${ }^{8}$ who reported highly significant associations between estimated fluoride ingestion from toothpaste and dental fluorosis.

\section{Materials and methods}

The study was conducted in two areas, fluoridated (F) Newcastle upon Tyne which has received drinking water containing $1 \mathrm{mg}$ F/L since 1969 and fluoride-deficient (FD) south Northumberland which has consistently received drinking water containing less than $0.1 \mathrm{mg}$ F/L. Approval for the study was obtained from the Local Research Ethics Committees and the Directors of Education.

In both areas, schools were chosen to provide children from a spectrum of socio-economic backgrounds. The number of participants required for the study was calculated assuming a $20 \%$ prevalence of fluorosis in Northumberland, a $40 \%$ prevalence in Newcastle and a 2:1 ratio of subjects starting to brush before and after one year of age. For an $\alpha$ of 0.05 and power of $80 \%, 474$ subjects would allow a $10 \%$ difference in the prevalence of fluorosis 
between those brushing before and after the age of 1 year to be detected in Northumberland and 375 subjects would allow a 15\% difference to be detected in Newcastle. The study took place between May and July 1998.

All parents of children in Year 4 (aged 8-9 years) in the chosen schools were given a letter, which incorporated a questionnaire and consent form. The questionnaire asked for information on: area of residence, continuity of residence in that area, use of fluoride drops and tablets, age when the child began to have their teeth brushed, frequency of brushing, type of toothpaste used and the quantity of toothpaste placed on the brush when the child's teeth were first brushed. The quantity of toothpaste applied was determined by reference to an illustration showing toothbrushes with one quarter, half, three quarters, and the entire toothbrush head covered with paste.

Children, whose parents had consented to take part in the study and were lifetime residents in the area, were then given a tube of toothpaste and a labelled, pre-weighed, sealed polythene bag containing a toothbrush to take home. Parents were asked to put the same amount of toothpaste on the brush that they had used when they first brushed their child's teeth. The toothbrush, together with the applied toothpaste, was then placed and sealed in the bag and returned to the school where it was weighed on a portable balance. The difference between the weight of the bag and brush before and after the toothpaste was applied indicated the amount of toothpaste placed on the brush by the parent. The toothbrush was returned to the children after weighing.

Children were examined by one dental examiner (DT) who had been trained and calibrated in the use of the Thylstrup and Fejerskov (TF) fluorosis index. ${ }^{12}$ The labial surfaces of the maxillary central incisors were wiped with a cotton wool roll and the lips were held away from the teeth for 1 minute. They were then photographed and examined clinically for fluorosis using the TF index. The clinical examination was performed in daylight, with the child facing a large window.

Photographs were taken of the maxillary incisors using a Nikon F 90 camera, Micro Nikkor $105 \mathrm{~mm}$ f 2.8 lens and a Nikon SB21 ring flash. The lens was used with an aperture of $\mathrm{f} 32$ to maximise the depth of field and was adjusted to give a reproduction ratio of 1:1. The camera was positioned at an angle of 30 degrees above a plane perpendicular to the labial surfaces of the central incisors. Only the top element of the flash unit was used to minimise specula reflection and the power was set to one quarter. Kodachrome Professional (64 ASA) 36 exposure transparency film from one batch was used for all participants. All films were processed in one batch at the end of the study. For both clinical and photographic examinations, the highest $\mathrm{TF}^{12}$ score given to either of the two labial surfaces of the maxillary central incisor teeth, was the value recorded for that child. No substitutes were included for absent central incisors.

The main purpose in taking photographs was to allow examination of teeth of children from both fluoridated and non-fluoridated areas, without the examiner being aware of which area the child was from. The colour transparencies were viewed by one examiner (DT) in random order, without reference to area of residence, on a graphics lightbox, without magnification.

Three to four weeks after the first examination, 1 in 20 children were re-photographed and clinically examined to assess examiner reproducibility.

The child's postcode was used to identify the electoral ward of residence and the Jarman UPA8 score, ${ }^{13}$ based on data for that ward from the 1991 Census, was then appended to the subject's data. The Jarman UPA8 score is calculated from ward-based data using eight weighted variables obtained from the percentages of: elderly living alone, children aged under five, one parent families, unskilled (social class V) workers, unemployed adults, over-

crowded houses, changes of address within 1 year and ethnic minorities. Higher scores represent more underprivileged areas.

Data from the questionnaires to parents, the weight of the toothpaste dispensed by the parents, the clinical and photographic scores and the Jarman scores were entered into a computer file and analysed using SPSS.

Reproducibility data were analysed using the Kappa statistic. Differences in the proportion of children with and without fluorosis were tested for statistical significance using the chi-squared test. The relative influence of the independent variables on the presence and absence of enamel fluorosis was determined using a backward stepping logistic regression model.

\section{Results}

The number of schools included in the study was 14 in Newcastle (F) and 15 in Northumberland (FD) (Table 1). The proportion of eligible children, lifetime residents with complete data, was 78\% in Newcastle (F) and 79\% in Northumberland (FD). The mean age of the children was 9.3 years $(\mathrm{SD}=0.47)$. In Newcastle $(\mathrm{F})$ and Northumberland (FD) $45 \%$ and $49 \%$ of the participants respectively were male.

The mean Jarman UPA8 score was $16.3(\mathrm{SD}=19.1)$ for subjects in Newcastle and $7.3(\mathrm{SD}=15.0)$ for Northumberland. This difference was statistically significant $(P<0.001)$ and suggested that the subjects from Newcastle tended to reside in more underprivileged areas than those in Northumberland.

Of the 439 children examined in Newcastle (F), 409 (93\%) had satisfactory photographic information available; in Northumberland the corresponding figure was 403 (94\%) out of 428 . There was good agreement between the clinical and photographic assessments in both Newcastle (Kappa $=0.68)$ and Northumberland $($ Kappa $=0.67)$ separately and combined $($ Kappa $=0.70)($ Table 2$)$. The intra-examiner reproducibility for the clinical examinations was excellent (Kappa $=0.73)$.

For subjects with both photographic and clinical data, fluorosis, of varying severity, was recorded on the maxillary central incisors of 312 (38\%) children by clinical examination and 298 (37\%) from photographs. For the children in Newcastle, these values were 54\% clinically and $52 \%$ photographically, while for Northumberland these figures were $23 \%$ and $21 \%$, respectively. Because of the close agreement between clinical and photographic scores, suggesting lack of bias in the clinical scoring between areas, throughout the remainder of this paper the TF values recorded by the clinical examination will be used.

The prevalence of fluorosis was 54\% in Newcastle (F) and 23\% in

Table I Profile of the response and eligibility of the subjects within the two study areas

Newcastle(F) Northumberland(FD)

Number of schools

Total number of children

Number of forms returned

Percentage of forms returned

Number of ineligible children

Number of eligible children

Number of non-consents

Number that did not

return toothbrush and paste

Number of absentees or unable

to examine

Number of children examined

Percentage of eligible children

examined

Number examined and

photographs acceptable

Percentage of eligible children

with complete data
15

709

585

$83 \%$

75

510

22

44

16

428

$84 \%$

$84 \%$

409

403

$78 \%$

$79 \%$ 


\begin{tabular}{|c|c|c|c|c|c|c|c|}
\hline & & & TF & om $p$ & aphs & & Total \\
\hline & & 0 & I & 2 & 3 & 5 & \\
\hline TF scores & 0 & 458 & 41 & I & 0 & 0 & 500 \\
\hline from clinical & I & 53 & 187 & 10 & I & 0 & 251 \\
\hline examinations & 2 & I & 10 & 31 & 2 & 0 & 44 \\
\hline & 3 & 2 & 0 & 3 & 8 & 3 & 16 \\
\hline & 5 & 0 & 0 & 0 & 0 & I & I \\
\hline Total & & 514 & 238 & 45 & 11 & 4 & 812 \\
\hline
\end{tabular}

Kappa $=0.70$

Northumberland (FD) (Table 3). In Newcastle, 222 (51\%) children had TF scores of 1 or 2 and only $15(3 \%)$ had a TF score of $\geq 3$. In Northumberland, 96 (22\%) children had a TF score of 1 or 2 and two $(0.5 \%)$ had a score of $\geq 3$.

In Newcastle (F), $263(60 \%)$ parents reported starting brushing their child's teeth before and $176(40 \%)$ at 12 months of age or later; for Northumberland (FD) the numbers were $260(61 \%)$ and $168(39 \%)$ respectively (Table 4$)$. The lack of association between the reported age of commencement of brushing and the distribution of clinical TF scores is shown in Table 4. In neither the fluoridated nor the fluoride-deficient area was there found a significant difference in the distribution of the TF scores between those who started to brush before or after 1 year of age $(P \geq 0.32)$.

The number of children reported to brush less than twice a day was $214(49 \%)$ in Newcastle (F) and 204 (48\%) in Northumberland (FD), and the numbers brushing twice a day or more were 225 $(51 \%)$ and $223(52 \%)$ respectively (Table 4$)$. In both Newcastle (F) and Northumberland (FD), there was no difference in the distribution of TF scores for subjects brushing twice a day or more and those brushing less than twice a day $(P \geq 0.33)$.

In Newcastle (F), $283(65 \%)$ reported using a pea sized amount (one quarter toothbrush head) or less of toothpaste when brushing commenced and 155 (35\%) used more than this amount (Table 4). The corresponding numbers for Northumberland (FD) were $279(65 \%)$ and $148(35 \%)$. There was no difference in the distribution of TF scores for subjects using a pea sized amount or less of toothpaste and those using more than a pea sized amount $(P \geq 0.17)$.

The actual weight of toothpaste applied to the toothbrush, as an estimate of the amount used when the child started to brush, was divided into two groups, $\leq 0.25 \mathrm{~g}$ and $>0.25 \mathrm{~g}$. The numbers of children in these two groups were $75(17 \%)$ and $364(83 \%)$ in Newcastle (F) and in Northumberland (FD) 63 (15\%) and 365 $(85 \%)$ respectively (Table 4$)$. There was no difference in the distribution of TF scores for subjects using more or less than $0.25 \mathrm{~g}$ of toothpaste in Newcastle although in Northumberland there was a tendency for subjects reporting to use more toothpaste to have less fluorosis $(P=0.06)$.

Parents were asked to indicate on the questionnaire whether they used a children's fluoride toothpaste, family fluoride toothpaste, non-fluoride toothpaste or no toothpaste when they started to brush. In Newcastle (F), 353 (82\%) of parents reported using a children's toothpaste and $77(18 \%)$ a family toothpaste (Table 4 ). Three parents reported using a non-fluoride toothpaste and two no toothpaste. In Northumberland (FD) the corresponding numbers of subjects were $339(81 \%), 81(19 \%), 4$ and 4 , respectively.

In Newcastle (F), 181 (51\%) participants who had used a children's toothpaste had a TF score $\geq 1$ compared with 51 (66\%) for those using a family toothpaste (Table 4 ). There was a significant difference in the distribution of TF scores with the type of toothpaste used, in Newcastle, with those who had used a children's toothpaste having significantly less fluorosis than those who had
Table 3 Distribution of subjects according to the TF index, ${ }^{12}$ measured clinically on the maxillary permanent central incisor teeth in the two study areas

The child's score is the highest score of the two teeth

\begin{tabular}{lcrcr}
\hline & \multicolumn{2}{c}{ Newcastle(F) } & \multicolumn{2}{c}{ Northumberland(FD) } \\
\hline TF Score & Number & $\%$ & Number & $\%$ \\
\hline & & & & \\
0 & 202 & 46 & 330 & 77 \\
1 & 182 & 42 & 89 & 21 \\
2 & 40 & 9 & 7 & 2 \\
3 & 14 & 3 & 2 & 1 \\
4 & 0 & 0 & 0 & 0 \\
5 & 1 & 0 & 0 & 0 \\
\hline Total & 439 & 100 & 428 & 100 \\
\hline
\end{tabular}

used a family toothpaste $(P=0.02)$. In Northumberland, (FD) there was little difference in the distribution of TF scores between the two groups $(P=0.76)$.

The association between the Jarman UPA8 score and the prevalence of fluorosis is shown in Table 4 . In both Newcastle $(P=0.04)$ and Northumberland $(P=0.003)$ there was an association between the individual's ward UPA8 score and fluorosis prevalence. Subjects in the most underprivileged wards tended to have less fluorosis than those in the more privileged wards, in both areas.

The age brushing started, brushing frequency, weight of paste used, type of toothpaste used, area of residence and Jarman score were entered into a logistic regression model with the presence or absence of fluorosis $(\mathrm{TF} \geq 1)$ as the outcome measure. Three variables - the area of residence $(P<0.001)$, Jarman score $(P=0.03)$ and type of toothpaste used $(P=0.02)$ were statistically significant. There were no statistically significant two-way interactions between the independent variables included in the model. The odds ratio of subjects having fluorosis from Newcastle compared with Northumberland was 4.5 (95\% CI 3.3-6.1) and subjects with higher Jarman scores were more likely to have fluorosis. The odds of a subject having fluorosis using an adult toothpaste compared with a children's was 1.6 (95\% CI 1.06-2.27). When the presence or absence of fluorosis was defined at the threshold TF $>2$, the only significant variable in the model was area of residence. The odds ratio of a subject having fluorosis in Newcastle compared with Northumberland was 7.1 (95\% CI 3.4-14.7).

\section{Discussion}

This and other studies in the UK have demonstrated that fluorosis is more prevalent in fluoridated than fluoride deficient areas. In fluoridated Newcastle, the overall prevalence of fluorosis was 54\% compared with $23 \%$ in Northumberland. The prevalence of fluorosis in Newcastle is identical to that found in fluoridated Anglesey ${ }^{14}$ but higher than in fluoridated Birmingham. ${ }^{8,15}$ In fluoride-deficient areas, the reported prevalence of fluorosis ranges from $8 \%{ }^{15}$ to $36 \% .{ }^{14}$ These differences in prevalence could reflect differences in 


\begin{tabular}{|c|c|c|c|c|c|c|c|c|c|c|c|c|}
\hline & \multicolumn{5}{|c|}{$\begin{array}{l}\text { Newcastle }(F) \\
\text { TF score }\end{array}$} & \multicolumn{7}{|c|}{$\begin{array}{l}\text { Northumberland (FD) } \\
\text { TF score }\end{array}$} \\
\hline & 0 & 1 & 2 & $3+$ & Total & & 0 & I & 2 & $3+$ & Total & \\
\hline \multicolumn{13}{|l|}{ Age started to brush } \\
\hline $\begin{array}{l}\text { Before } 12 \text { months } \\
\text { At } 12 \text { months or later }\end{array}$ & $\begin{array}{c}114 \\
(43.3) \\
88 \\
(50.0)\end{array}$ & $\begin{array}{c}118 \\
(44.9) \\
64 \\
(36.4)\end{array}$ & $\begin{array}{c}22 \\
(8.4) \\
18 \\
(10.2)\end{array}$ & $\begin{array}{c}9 \\
(3.4) \\
6 \\
(3.4)\end{array}$ & $\begin{array}{l}263 \\
(100) \\
176 \\
(100)\end{array}$ & $P=0.35$ & $\begin{array}{c}197 \\
(75.8) \\
133 \\
(79.2)\end{array}$ & $\begin{array}{c}59 \\
(22.7) \\
30 \\
(17.9)\end{array}$ & $\begin{array}{c}3 \\
(1.2) \\
4 \\
(2.4)\end{array}$ & $\begin{array}{c}\text { I } \\
(0.4) \\
I \\
(0.6)\end{array}$ & $\begin{array}{l}260 \\
(100) \\
168 \\
(100)\end{array}$ & $P=0.32^{*}$ \\
\hline $\begin{array}{l}\text { Brushing frequency } \\
\text { Brushed less than } \\
\text { twice per day } \\
\text { Brushed twice per } \\
\text { day or more }\end{array}$ & $\begin{array}{c}101 \\
(47.2) \\
101 \\
(44.9)\end{array}$ & $\begin{array}{c}88 \\
(41.1) \\
94 \\
(41.8)\end{array}$ & $\begin{array}{l}20 \\
(9.3) \\
20 \\
(8.9)\end{array}$ & $\begin{array}{c}5 \\
(2.3) \\
10 \\
(4.4)\end{array}$ & $\begin{array}{c}214 \\
(100) \\
225 \\
(100)\end{array}$ & $P=0.66$ & $\begin{array}{c}160 \\
(78.4) \\
169 \\
(75.8)\end{array}$ & $\begin{array}{c}38 \\
(18.6) \\
51 \\
(22.9)\end{array}$ & $\begin{array}{c}4 \\
(2.0) \\
3 \\
(1.3)\end{array}$ & $\begin{array}{c}2 \\
(1.0) \\
0 \\
(0)\end{array}$ & $\begin{array}{c}204 \\
(100) \\
223 \\
(100)\end{array}$ & $P=0.33^{*}$ \\
\hline $\begin{array}{l}\text { Amount of paste } \\
\text { Used a pea sized } \\
\text { amount of toothpaste } \\
\text { Used more than a pea } \\
\text { sized amount }\end{array}$ & $\begin{array}{c}129 \\
(45.6) \\
72 \\
(46.5)\end{array}$ & $\begin{array}{c}125 \\
(44.2) \\
57 \\
(36.8)\end{array}$ & $\begin{array}{l}22 \\
(7.8) \\
18 \\
(11.6)\end{array}$ & $\begin{array}{c}7 \\
(2.5) \\
8 \\
(5.2)\end{array}$ & $\begin{array}{l}283 \\
(100) \\
155 \\
(100)\end{array}$ & $P=0.17$ & $\begin{array}{c}217 \\
(77.8) \\
112 \\
(75.7)\end{array}$ & $\begin{array}{c}56 \\
(20.1) \\
33 \\
(22.3)\end{array}$ & $\begin{array}{c}5 \\
(1.8) \\
2 \\
(1.4)\end{array}$ & $\begin{array}{c}\text { I } \\
(0.4) \\
\text { I } \\
(0.7)\end{array}$ & $\begin{array}{c}279 \\
(100) \\
148 \\
(100)\end{array}$ & $P=0.89^{*}$ \\
\hline $\begin{array}{l}\text { Toothpaste weight } \\
\text { Toothpaste weight } \\
0.25 \mathrm{~g} \text { or less } \\
\text { Toothpaste weight } \\
\text { more than } 0.25 \mathrm{~g}\end{array}$ & $\begin{array}{c}36 \\
(48.0) \\
166 \\
(45.6)\end{array}$ & $\begin{array}{c}31 \\
(4 I .3) \\
I 5 I \\
(4 I .5)\end{array}$ & $\begin{array}{c}7 \\
(9.3) \\
33 \\
(9.1)\end{array}$ & $\begin{array}{c}1 \\
(1.3) \\
14 \\
(3.8)\end{array}$ & $\begin{array}{c}75 \\
(100) \\
364 \\
(100)\end{array}$ & $P=0.75$ & $\begin{array}{c}42 \\
(66.7) \\
288 \\
(78.9)\end{array}$ & $\begin{array}{c}18 \\
(28.6) \\
71 \\
(19.5)\end{array}$ & $\begin{array}{c}2 \\
(3.2) \\
5 \\
(1.4)\end{array}$ & $\begin{array}{c}1 \\
(1.6) \\
I \\
(0.3)\end{array}$ & $\begin{array}{c}63 \\
(100) \\
365 \\
(100)\end{array}$ & $P=0.06^{*}$ \\
\hline $\begin{array}{l}\text { Toothpaste type } \\
\text { Used children's } \\
\text { toothpaste } \\
\text { Used family. } \\
\text { toothpaste }\end{array}$ & $\begin{array}{c}172 \\
(48.7) \\
26 \\
(33.8)\end{array}$ & $\begin{array}{c}134 \\
(38.0) \\
44 \\
(57.1)\end{array}$ & $\begin{array}{c}33 \\
(9.3) \\
6 \\
(7.8)\end{array}$ & $\begin{array}{c}14 \\
(4.0) \\
I \\
(1.3)\end{array}$ & $\begin{array}{c}353 \\
(100) \\
77 \\
(100)\end{array}$ & $P=0.02$ & $\begin{array}{c}263 \\
(77.6) \\
62 \\
(76.5)\end{array}$ & $\begin{array}{c}68 \\
(20.1) \\
18 \\
(22.2)\end{array}$ & $\begin{array}{c}6 \\
(1.8) \\
1 \\
(1.2)\end{array}$ & $\begin{array}{c}2 \\
(0.6) \\
0 \\
(0)\end{array}$ & $\begin{array}{c}339 \\
(100) \\
81 \\
(100)\end{array}$ & $P=0.76^{*}$ \\
\hline \multicolumn{13}{|l|}{ Jarman UPA8 Score } \\
\hline-28.02 to 3.32 & $\begin{array}{c}55 \\
(41.7)\end{array}$ & $\begin{array}{c}57 \\
(43.2)\end{array}$ & $\begin{array}{c}16 \\
(12.1)\end{array}$ & $\begin{array}{c}4 \\
(3.0)\end{array}$ & $\begin{array}{l}132 \\
(100)\end{array}$ & & $\begin{array}{c}114 \\
(70.4)\end{array}$ & $\begin{array}{c}44 \\
(27.2)\end{array}$ & $\begin{array}{c}3 \\
(1.9)\end{array}$ & $\begin{array}{c}1 \\
(0.6)\end{array}$ & $\begin{array}{l}162 \\
(100)\end{array}$ & \\
\hline
\end{tabular}

* Chi-squared statistic calculated after combining TF scores 2 and $3+$ because of low cell counts

${ }^{\dagger}$ Based on Kendall tau $b$ for the association between individuals TF score and Jarman score (continuous)

the application of diagnostic criteria, sampling method or fluoride ingestion.

Children from more deprived areas were found to be at lower risk of developing fluorosis confirming the association found in other studies. ${ }^{8,16}$ The reasons for this are not clear but, if it is accepted that the lesions identified as fluorosis are indeed the result of increased ingestion of fluoride, it must be assumed that either subjects from less deprived areas are consuming more fluoride or they are more sensitive to its effects. Indeed, it has been well documented that young children in less deprived areas commence brushing earlier and more frequently than children in more deprived areas. ${ }^{17}$ It is suggested, therefore, that the most likely source of additional fluoride in the less deprived populations is from oral care products.

A number of studies have demonstrated an association between early toothpaste ingestion and fluorosis, particularly in fluoridated areas - the age brushing commenced, ${ }^{5-9}$ the amount of toothpaste used, ${ }^{8,10,18,19}$ the concentration of fluoride ${ }^{8,20}$ and the frequency of brushing 8,21 have all been identified as risk factors. The present study failed to replicate these associations apart from in Newcastle where children who were reported to have used a children's toothpaste had less fluorosis than those who had used an adult toothpaste. Most of the difference between the two groups was in subjects with the earliest signs of fluorosis (TF 1). Indeed, more subjects who were reported to have used a children's toothpaste $(13.3 \%)$ had TF scores of 2 or more than those using an adult dentifrice $(9.1 \%)$. However, this difference was not statistically significant.

This study used methods very similar to those used by Rock and Sabieha. ${ }^{8}$ While the results of these two studies agree that prevalence of fluorosis was lower in children from deprived social backgrounds and higher in children who began brushing with an adult toothpaste, the present study failed to replicate the previous study's findings ${ }^{8}$ regarding toothbrushing habits in early childhood discussed above. Reasons for these disagreements are unclear but the most likely explanations are difficulties associated with retrospective studies. In both Newcastle and Northumberland, $81 \%$ of parents reported that their child used a children's toothpaste when brushing commenced. Although an effort was made to identify the type of toothpaste used more precisely, most of the answers provided were too vague to use. A previous study, involving children aged 1.5 to 2.5 years, reported that only $34 \%$ of children in the North of England used a children's toothpaste. ${ }^{17}$ The validity of data based on parental recall of oral health behaviour many years earlier has been questioned. ${ }^{22}$ Moreover, even if accurate data could be collected, it is not necessarily the amount of toothpaste placed on the brush that determines fluorosis risk but the amount swallowed. Only a prospective study with careful monitoring of participants can address this issue.

Previous studies have suggested that TF scores of 3 or more are generally considered to be aesthetically unacceptable 23,24 whereas earlier stages of fluorosis have, in some circumstances, 
been perceived as aesthetically beneficial. In this study, TF scores of 3 or more were recorded in $3.4 \%$ of children in Newcastle and only two children in Northumberland. Such levels of fluorosis cannot be considered a public health problem. However, reducing even these low levels of prevalence would seem to be desirable. Parents should be encouraged to supervise toothbrushing by young children, use small amounts (pea or smear) of fluoride toothpaste and encourage the spitting out of waste slurry. The use of toothpastes containing low concentrations of fluoride may be appropriate for children considered to be at low caries risk and / or living in a fluoridated area to minimise fluorosis risk, ${ }^{25}$ although the possibility of slightly reduced caries protection should be borne in mind.

1 Szpunzar S M, Burt B A. Trends in the prevalence of dental fluorosis in the United States. A review. J Public Health Dent 1987; 47: 71-79.

2 Pendrys D G, Stamm J W. Relationship of total fluoride intake to beneficial effects and enamel fluorosis. J Dent Res 1990; 69: 529-538.

3 Clark D C. Trends in prevalence of dental fluorosis in North America. Community Dent Oral Epidemiol 1994; 22: 148-152.

4 Holloway P J, Ellwood R P. The prevalence, causes and cosmetic importance of dental fluorosis in the United Kingdom: a review. Community Dent Health 1997; 14: 148-155.

5 Osuji O D, Leake J L, Chipman M L, Nikiforuk G, Locker D, Levine N. Risk factors for dental fluorosis in a fluoridated community. J Dent Res 1988; 67: 1488-1492.

6 Milsom K, Mitropoulos C M. Enamel defects in 8 year old children in fluoridated and non-fluoridated parts of Cheshire. Caries Res 1990; 24: 286-289.

7 Lalumandier J A, Rozier R G. The prevalence and risk factors of fluorosis among patients in a paediatric practice. Paediatr Dent 1995; 17: 19-25.

8 Rock W P, Sabieha A M. The relationship between reported toothpaste use in infancy and fluorosis of permanent incisors. Br Dent $J$ 1997; 183: 165-170.

9 Wang N J, Gropen A M, Ogaard B. Risk factors associated with fluorosis in a non-fluoridated population in Norway. Community Dent Oral Epidemiol 1997; 25: 396-401.
10 Pendrys D G. Risk of fluorosis in a fluoridated population. Implications for the dentist and hygienist. J Am Dent Ass 1995; 126: 1617-1624.

11 Riordan P J. Dental fluorosis, dental caries and fluoride exposure among 7-year-olds. Caries Res 1993; 27: 71-77.

12 Thylstrup A, Fejerskov O. Clinical appearance of dental fluorosis in permanent teeth in relation to histological changes. Community Dent Oral Epidemiol 1978; 6: 315-328

13 Jarman B. Identification of underprivileged areas. Br Med J 1983; 286: 1705-1709.

14 Ellwood R P, O'Mullane D M. Dental enamel opacities in three groups with varying levels of fluoride in their drinking water. Caries Res 1995; 29: 137-142.

15 Hamdan M, Rock W P. The prevalence of enamel mottling on incisor teeth in optimal and low fluoride communities in England. Community Dent Health 1991; 8: 111-119.

16 Ellwood R P, O'Mullane D M. The demographic and social variation in the prevalence of dental enamel opacities in North Wales. Community Dent Health 1994; 11: 192-196.

17 Hinds K, Gregory J R. National diet and nutrition survey: children aged 1.5 to 4.5 years. Volume 2: Report of the Dental Survey. London: HMSO, 1995.

18 Evans D J. A study of developmental defects in enamel in 10-year-old high social class children residing in a non fluoridated area. Community Dent Health 1991;31-38.

19 Skotowski M C, Hunt R J, Levy S M. Risk factors for dental fluorosis in paediatric dental patients. J Public Health Dent 1995; 55:154-159.

20 Holt R D, Morris C E, Winter G B, Downer M C. Enamel opacities and dental caries in children who used a low fluoride toothpaste between 2 and 5 years. Int Dent J 1994; 44: 331-341.

21 Pendrys D G, Katz R V, Morse D E. Risk factors for enamel fluorosis in a fluoridated population. Am J Epidemiol 1994; 140: 461-471.

22 Kwan S Y L, Williams S A. The reliability of interview data for age at which infants' toothcleaning begins. Community Dent Oral Epidemiol 1998; 26: 214-218.

23 Hawley G M, Ellwood R P, Davies R M. Dental caries, fluorosis and the cosmetic implications of different TF scores in 14-year-old adolescents. Community Dent Health 1996; 13:189-192.

24 Riordan P J. Perceptions of dental fluorosis. J Dent Res 1993; 72: 1268-1274.

25 British Society of Paediatric Dentistry. A policy document on fluoride dietary supplements and fluoride toothpastes for children. Int J Paed Dent 1996; 6: 139-142. 